\title{
Identifying the main uncertainty drivers of energy security in a low- carbon world: The case of Europe
}

\author{
Céline Guivarchํㅗ Stéphanie Monjon²3
}

Note: this text is a post-print from Guivarch, Céline, and Stéphanie Monjon. 2016. "Identifying the main uncertainty drivers of energy security in a low-carbon world: The case of Europe ». Energy Economics. doi:10.1016/j.eneco.2016.04.007.

\begin{abstract}
This analysis contributes to recent efforts to better understand the evolution of energy security in a lowcarbon world. Our objective was to assess how energy security may change over the course of the century, and to what extent these changes depend on the uncertainty of the factors that drive the evolution of energy systems, including future technologies, improved energy efficiency, fossil fuel resources and markets, and economic growth. To this end, we focused on Europe and on a set of energy security indicators based on three perspectives: sovereignty, robustness and resilience. A database of scenarios allowed us to account for the large uncertainties surrounding the determinants of future energy systems. We then analyzed the way energy security indicators evolve over time, and how their trajectories vary across scenarios. We identified the indicators that vary the most between scenarios, i.e. the indicators whose future evolution is the most uncertain. For these indicators, we performed an analysis of variance to estimate the contribution of each driver to the uncertainty of the indicators. The paper shows that the European double target of significantly decreasing $\mathrm{CO}_{2}$ emissions and increasing the security of the supply of energy may be difficult to reach. Nevertheless, some levers could facilitate the transition to a low-carbon society while improving energy security, or by limiting its degradation. The results emphasize the importance of policies in favor of low or zero carbon technologies in power generation, but also the differences in their contributions to the complete uncertainty of the indicators. Policies promoting energy efficiency also play a role but only in the resilience of TPES. These policies are thus important levers for mitigating the negative impacts of climate policies on energy security.
\end{abstract}

Keywords: Climate policy, energy security, Europe, scenarios database, sovereignty, robustness, resilience.

JEL Classification: Q43, Q47, Q54

\section{Acknowledgement}

\footnotetext{
${ }_{1}^{1}$ CIRED, 45bis avenue de la belle Gabrielle, 94736 Nogent-sur-Marne, France. Email : guivarch@centre-cired.fr.

2 Université Paris Dauphine, PSL Research University, LEDa, 75016 Paris, France, CIRED and CEPII. Email : stephanie.monjon@dauphine.fr

${ }^{3}$ Corresponding author.
} 
The development of the Imaclim-R model was supported by the Chair 'Modeling for sustainable development', led by MINES ParisTech, Ecole des Ponts ParisTech, AgroParisTech and financed by ADEME, EDF, GRTgaz and SCHNEIDER ELECTRIC. The views expressed in this article are the authors' and do not necessarily reflect the views of the aforementioned institutions. 


\section{Introduction}

In 2008, the Lisbon Treaty launched new climate and energy policies in the European Union with the aim of significantly decreasing $\mathrm{CO}_{2}$ emissions, while increasing the security of the supply of energy in the Union, at reasonable costs in order to maintain competitiveness. Since then, climate policy and energy security policy have been closely linked in the EU, as detailed in the European Energy Roadmap 2050 (European Commission, 2011).

Today it is clear that the two issues are intertwined. They share a common root cause, the demand for energy, but the solutions for improving energy security and reducing greenhouse gases (GHG) are not necessarily the same, and may involve some contradictions. For instance, the deployment of renewable energies led to greater dependency on natural gas for peak load and back-up, especially on Russian gas. The recent geopolitical crises between Russia and Ukraine revealed the vulnerability of European energy on this respect.

Energy security does not only refer to geopolitical risks or dependency on primary fuels but is multifaceted. Several recent contributions proposed an analytical framework to evaluate the concept by incorporating different dimensions or perspectives of energy security (APERC, 2007; Cherp et al., 2012; Winzer, 2012). In this paper, we use the framework developed by the Global Energy Assessment (Cherp et al., 2012). The starting point of this approach is to work with a definition of energy security that incorporates the likely radical transformations of energy systems in the long term. Energy security is defined as the low vulnerability of vital energy systems. Even if the security of oil supplies remains important, contemporary energy security policies must also address other energy systems. This point is crucial in the current context in which many stakeholders call for speeding up the energy transition. Vital energy systems thus refer to different energy carriers (electricity, hydrogen, liquid and synthetic fuels), or to the total energy supply.

Several papers recently used this framework to explore the consequences of climate policies for energy security from a long-term perspective (Cherp et al., 2013; Jewell et al., 2013, 2014; Guivarch et al., 2015). These analyses show that the implementation of ambitious climate policies affects vital energy systems differently. They also emphasize the importance of the time dimension. For instance, Guivarch et al. (2015) showed that the impact of climate policies is mixed in the short term and globally good in the medium term, whereas in the long term, there is a risk of degradation of energy security, especially related to the electricity system.

The objective of this paper is thus to highlight levers that could improve energy security, or limit its degradation, if ambitious climate policies are implemented. This is a companion paper to Guivarch et al. (2015). In the present paper, we take a close series of energy security indicators and analyze their dynamics over the course of the present century in a low-carbon world. We aim to identify the main drivers of these dynamics among key low and zero carbon technologies, the evolution of energy efficiency, fossil fuel resources and markets and economic growth. The positive or negative impacts of ambitious climate policies on energy security may depend on the evolution of some drivers of the 
uncertainty of future energy systems. ${ }^{4}$ For instance, the availability and affordability of carbon capture and storage (CCS) technologies would make the use of coal possible in a low-carbon world, while improving energy security for coal-producing countries. Without being sure of succeeding in developing low-carbon technologies, public policies will play a crucial role in their future availability and cost. This is also true of energy efficiency and for economic growth.

The paper describes an original methodology to investigate these issues. Using the energy-economyenvironment model, Imaclim- $R$, we created a database of long-term scenarios in which different determinants of future energy systems, on both the supply and demand side, are considered. Each scenario describes a possible future in terms of economic growth, fossil fuel availability, energy efficiency and the cost and the availability of different low-carbon technologies. For each possible future, we imposed a global $\mathrm{CO}_{2}$ emission trajectory leading to the stabilization of the concentration of $\mathrm{CO}_{2}$ in the atmosphere at $550 \mathrm{ppm} \mathrm{CO}_{2}$-eq. A set of indicators that capture the multi-faceted aspect of the energy security concept were assessed in each scenario, enabling us to analyze the evolution of the indicators in all possible future worlds, and their dispersion over the course of the century. By focusing on the indicators with the widest dispersion, and by applying a multi-factor analysis of variance (ANOVA), we identified the main explanatory factors. The analysis was applied to Europe and identified the most important drivers of energy security indicators in a low-carbon world. The method identified some levers that could be used to improve energy security if ambitious climate policies are implemented.

Section 2 is a brief review of the literature exploring the impacts of climate policies on long term energy security. In Section 3, we explain our contribution and detail the method we used. We present the series of indicators used for the analysis and the energy-economy-environment model, Imaclim- $R$, used for the simulations. We explain how we built our database of scenarios and the tools we used to analyze the results of the simulations. In Section 4, we present the results: first, the dynamics of the indicators in all the scenarios for the whole century and the assessment of their dispersion; second, the contributions of the different drivers to this dispersion with an analysis of variance. In Section 5 we discuss our results and conclude.

\section{Climate policy and energy security: recent advances}

Although the issue of energy security is high on the policy agenda and pervasive in the discourse, it is seldom accompanied by a clear definition of the term. As explained in Winzer (2012), the concept of energy security is "blurred", "elusive" or "slippery". This is partly due to its multi-faceted nature. The assessment of energy security thus implies developing an analytical framework to identify the different dimensions of the concept. Several recent contributions proposed different frameworks (APERC, 2007; Cherp et al., 2012; Winzer, 2012).

In this paper, we use the framework developed by the Global Energy Assessment (GEA) in a series of recent papers that specifically examined the effect of climate policies on energy security worldwide and in

\footnotetext{
${ }^{4}$ The term uncertainty is used here like Saltelli (2002) who defined it as "Sensitivity analysis is the study of how the uncertainty in the output of a model (numerical or otherwise) can be apportioned to different sources of uncertainty in the model input".
} 
different regions (Cherp et al., 2013; Jewell et al., 2013, 2014; Guivarch et al., 2015). The aim of the analytical framework is to assess the "new" energy security dealing with tensions in the supply of natural gas in Europe, the increasing demand for energy in Asia, and the transition towards low-carbon societies that began in the 2000s. The analytical framework is based on a definition of energy security that is sufficiently flexible to include the likely future transformation of energy systems in the long term. Energy security refers to the low vulnerability of vital energy systems. These systems comprise not only primary fossil fuels but also different energy carriers (electricity, hydrogen, liquid and synthetic fuels), which will play an increasing role in a low-carbon world. The GEA approach aims to identify the vulnerabilities of these systems, from three perspectives: sovereignty, robustness and resilience. The sovereignty perspective refers to threats posed by external actors and the exposure of a region/country to such threats (Cherp and Jewell, 2011). It is related to past events such as energy embargoes or price manipulations and to foreign control of energy resources. From this perspective, energy security is generally evaluated through the reliance of a region on imported energy sources or, at a more global level, through international trade in energy. The robustness perspective deals with natural and technological to energy systems. Historically, it is related to major accidents, electricity blackouts and resource scarcity. The resilience perspective focuses on the ability of the energy systems to resist diverse disruptions caused by social and economic factors that are difficult to predict and control (political instability, price volatility, etc). From a resilience perspective, the future is unpredictable. This future uncertainty can be related to markets, technologies and societies. From this perspective, energy security can be apprehended in terms of the range of energy options. The risks apprehended by the framework we use refer not only to traditional ones, like geopolitical risks, but also to new challenges, for instance those posed by the development of electricity systems.

Cherp et al. (2013) envisaged different levels of ambition in reducing world GHG emissions and introduced uncertainties by considering different levels of GDP growth and of the availability of fossil resources. These different scenarios were simulated in two different integrated assessment models. These authors found that climate mitigation policies will increase the resilience of energy systems as reflected in their diversity, and will improve sovereignty around the middle of the century when low-carbon and fossil energy source co-exist. Climate policies will enable deep penetration of solar energy in the electric sector and of bio-fuels in the liquid fuel sectors, which will reduce diversity by the end of the century.

Jewell et al. (2013) examined the future evolution of energy security in major economies: China, India, the European Union and the United States of America. Their analysis is based on results of six integrated assessment models. In each model, two temperature limitation targets are considered: an increase of $3{ }^{\circ} \mathrm{C}$, and an increase of $2{ }^{\circ} \mathrm{C}$. Their results conclude that different regions share common trends. For instance, climate policies reduce energy imports and increase the diversity of energy options. But the major economies would also be exposed to specific changes. For instance, in the EU, climate policies would decrease dependence on imports, while increasing the diversity of energy options in the transport sector. With climate policies, China would not completely exhaust its oil and gas reserves, thereby allowing it to avoid becoming completely dependent on imports of these products.

Jewell et al. (2014) explored low-carbon scenarios to limit the global mean temperature increase to $2^{\circ} \mathrm{C}$ above the pre-industrial level by 2100 . Three elements differ among the scenarios: the availability of some 
low carbon energy sources (solar and wind, biomass, nuclear energy etc.), improvement of energy efficiency, and the availability of advanced transport technologies. The sovereignty perspective is evaluated by global trade in energy, some regional energy balances, and trade in individual fuels. The resilience perspective is evaluated by world energy intensity and the diversity of the primary energy supply at international and regional levels. These authors found that low-carbon scenarios are associated with lower trade in energy and increased diversity of energy options than in the baseline scenario, but that a few risks emerge in the second half of the century due to high trade in natural gas and hydrogen and limited range of sources of electricity. Indeed, in some low-carbon scenarios, the levels of gas trade are equivalent to the levels of oil trade today. However, gas would not dominate any particular sector as oil dominates the transport sector today. Other indicators suggest an improvement in energy security in the low-carbon scenarios.

Guivarch et al. (2015) investigated the effect of climate policies on energy security indicators at three specific time horizons, 2025, 2050 and 2075. This analysis focused on the relative variation in energy security indicators between a case with climate policies and a case without climate policies. The results showed that very few indicators of energy security, e.g. the ratio of oil production to resources and energy intensity, are unambiguously improved by climate policies. Others are degraded either at a certain time horizon, or in certain scenarios. For instance, indicators of the sovereignty perspective, which are all improved, on average, from the medium term on, may be degraded in some scenarios. Moreover, tensions concerning some aspects of energy security could emerge around 2025, which is a critical period for international climate negotiations. The paper also showed that there is a risk of degradation of energy security in the long term, due to the greater use of electricity carriers and greater concentration of primary sources for the generation of power. Lastly, the paper pointed out that the dispersion of the indicators tends to increase with the time horizon and briefly explored the issue in the medium term.

\section{Contribution and method}

The aim of the present paper is to contribute to recent efforts to improve our understanding of the impact of climate policies on energy security. Our objective is to assess how energy security indicators could evolve in a low-carbon world, and to what extent changes depend on the uncertainty surrounding the factors that drive the evolution of energy systems, such as future technologies, improved energy efficiency, fossil fuel resources and markets, and economic growth. ${ }^{5}$ To our knowledge, this issue has not been explored to date.

To examine the evolution of energy security in a low-carbon world, we focused on Europe and on a small number of energy security indicators. We evaluated the evolution of these indicators up to 2075 in a database of long-term scenarios built with the energy-economy-environment model, Imaclim-R. To explore the relevant uncertainty factors, we constructed a large set of scenarios, following a method previously described in Rozenberg et al. (2014). We identified the main driving forces (or main uncertainty drivers) that affect the future outcomes of the systems, e.g. learning potentials and the costs of key

\footnotetext{
${ }^{5}$ We are interested in the absolute values of energy security indicators, and not in their variations compared to a reference scenario.
} 
technologies. We translated these driving forces into model parameters, and combined them to build a large number of model runs. This process led us to build what we call a "scenario database". In all the scenarios, we imposed a global $\mathrm{CO}_{2}$ emission trajectory leading to the stabilization of the $\mathrm{CO}_{2}$ concentration in the atmosphere at $550 \mathrm{ppm} \mathrm{CO}_{2}$-eq. ${ }^{6}$ It was then possible to analyze the way energy security indicators evolve over time in each scenario, and how their trajectories differ among the scenarios. We identified the indicators that vary the most between scenarios, i.e. the indicators that have the most uncertain evolution. For those indicators, we analyzed the contribution of each driver to their uncertainty, with an analysis of variance. In this section, we present the indicators, the model Imaclim- $R$, and the uncertainty drivers on which the database of scenarios is based. We then explain the tools we used to analyze the dispersion of the indicators.

\section{The indicators}

As explained above, we used the GEA's analytical framework based on three perspectives. Within this framework, several indicators are appropriate to inform on a perspective of a specific energy system. Although they used the same assessment framework, Cherp et al. (2013), Jewell et al. (2013) and Jewell et al. (2014) selected somewhat different indicators depending on the models or the objective targeted. In this paper, our selection of indicators results in a trade-off proposing (i) a limited number of indicators to ensure the results are readable, (ii) a variety of indicators covering the different perspectives of the energy security concept, (iii) indicators that can be calculated with the model IMACLIM-R. Moreover, all our indicators are representative of the indicators frequently discussed in the literature. ${ }^{7}$ Table 1 lists the indicators selected. ${ }^{8}$

Table 1 - Vulnerabilities of vital energy systems and related indicators

\begin{tabular}{|c|c|c|c|}
\hline Vital energy systems & $\begin{array}{c}\text { Sovereignty } \\
\text { perspective }\end{array}$ & $\begin{array}{c}\text { Robustness } \\
\text { perspective }\end{array}$ & $\begin{array}{c}\text { Resilience } \\
\text { perspective }\end{array}$ \\
\hline $\begin{array}{c}\text { Total primary energy } \\
\text { supply }\end{array}$ & $\begin{array}{c}\text { Share of imports in } \\
\text { TPES }\end{array}$ & $/$ & $\begin{array}{c}\text { Energy intensity of } \\
\text { GDP }\end{array}$ \\
\hline $\begin{array}{c}\text { Primary fuels: oil, } \\
\text { coal, gas }\end{array}$ & $\begin{array}{c}\text { Regional import } \\
\text { dependence }\end{array}$ & $\begin{array}{c}\text { Production/Resource } \\
\text { ratio }^{9}\end{array}$ & $\begin{array}{c}\text { Concentration of } \\
\text { markets }^{10}\end{array}$ \\
\hline Electricity carrier & Share of imports for & Share of renewable & Concentration of $^{2}$ \\
\hline
\end{tabular}

\footnotetext{
${ }^{6}$ The emission target chosen lies between two Representative Concentration Pathways (RCP): RCP 2.6 and RCP 4.5. RCP 2.6 is a very low trajectory and can only be reached with rather specific assumptions. We explored the scenarios with an emission trajectory leading to high probability of remaining below $2^{\circ} \mathrm{C}$ (consistent with a RCP 2.6 trajectory) but more than a third of the scenarios do not run until the end of the time horizon due to the stringency of the constraint. This emission target would not have allowed us to fully explore the variance of results and its determining factors. Conversely, RCP4.5 is a relatively high trajectory, not a very ambitious mitigation path. The emission target we chose thus lies between RCP 2.6 and RCP 4.5, which is interesting from a policy perspective because mitigation costs differ substantially between forcing levels of $2.6 \mathrm{~W} / \mathrm{m} 2$ and $4.5 \mathrm{~W} / \mathrm{m} 2$ (Krey et al., 2014).

7 The indicators selected are very close to those used in Guivarch et al. (2015).

${ }^{8}$ All the indicators were defined such that an increase (respectively a decrease) in their value indicates a worsening (respectively an improvement) of the dimension of energy security they measure.

${ }^{9}$ The model only evaluates this indicator for oil.

10 The model only evaluates this indicator for oil.
} 


\begin{tabular}{|l|l|c|c|}
\hline generating power & & $\begin{array}{c}\text { energies in electricity } \\
\text { production (excluding } \\
\text { biomass and hydro) }\end{array}$ & $\begin{array}{c}\text { primary energy } \\
\text { sources used for } \\
\text { electricity production }\end{array}$ \\
\hline
\end{tabular}

The total primary energy supply (TPES) is the first vital energy system we analyzed. The sovereignty perspective is apprehended by the share of TPES imports that measures the dependence of the energy supply on imports. From a resilience perspective, the energy intensity of GDP is measured by the ratio of TPES to GDP. It informs about the amount of energy required to generate the GDP of the region. The more energy the economic activity of a country requires, the more it will be exposed to diverse disruptions due to social and economic factors.

Primary fuels (oil, gas and coal) are the second vital energy system we examined. The sovereignty perspective is evaluated by net imports of oil, gas and coal into the region. The robustness perspective is apprehended by the ratio of oil production to oil resources. ${ }^{12}$ The resilience perspective is measured by the global concentration of suppliers of oil. We used the Herfindahl-Hirschmann index, calculated as the sum of squared market shares of oil producers. Note that this index increases when the market is dominated by a small number of producers. These two indicators are global, not specific to Europe. ${ }^{13}$

The last vital energy system we analyzed is the electricity carrier. From a sovereignty perspective, the vulnerability of European electricity production is evaluated through its reliance on imported fuels as primary sources for the generation of power. The robustness perspective is apprehended by the share of renewable energies in electricity production by excluding biomass and hydroelectric electricity. ${ }^{14}$ The integration of large amounts of intermittent energies into the electrical grid is technically complex and could make the network more vulnerable (Quoc Hung et al., 2016). ${ }^{15}$ This indicator thus highlights an important aspect of future energy security. The concentration of primary energy sources, measured by the Herfindahl-Hirschmann index of the shares of the different primary sources, informs on the resilience of the electricity generation capacity. This index increases when a smaller number of sources are responsible for a large share of the generation, i.e. when the diversity of the mix decreases.

All the indicators provide useful information on the energy security of a region but their importance may change depending on the time horizon. In the short term, primary fuels indicators are certainly those that should be examined as carefully as possible, while electricity indicators become crucial in the longer

\footnotetext{
${ }^{11}$ When assessing the rate of energy independence, uranium is conventionally not included in imported fuels. We applied the same rule.

12 It is more common to present the inverse ratio, i.e. the ratio of resources to production, expressed in years of reserves remaining at the current rate of extraction. However, we use the ratio of production to resources, so that the value of the indicator increases with a decrease in availability.

13 In our modeling framework, oil trade is not modeled bilaterally but via an international pool.

14 The development of renewable energy capacities improves the energy security of a region, especially by reducing dependence on imported fossil fuels. Nevertheless, renewable energies are not the only way to decrease the imports of fossil fuels and this aspect is taken into account with the previous indicators of the resilience perspective.

15 The expected major increase in the contribution of renewable energies to power generation is mainly due to the increase in intermittent energies (solar, onshore and offshore wind). See for instance DNV GL et al. (2014) for projections in 2025 and 2030.
} 
term. The TPES indicators give a more global view of the energy needs of a region and play an important role non-stop.

\section{The model ${ }^{16}$}

The Imaclim-R model (Waisman et al., 2012) is a multi-region and multi-sector model of the world economy that represents the intertwined evolution of technical systems, energy demand behavior and economic growth. It combines a computable general equilibrium (CGE) framework with bottom-up sectoral modules in a hybrid and recursive dynamic architecture. In addition, it describes growth patterns in second best worlds with market imperfections, partial uses of production factors, and imperfect expectations. The model represents endogenous GDP and structural change, energy markets and induced technical change. The scope of GHG gases represented is restricted to $\mathrm{CO}_{2}$ emissions from fossil fuel combustion.

The model is disaggregated into twelve regions and twelve sectors, including five energy sectors: coal, oil, gas, refined products and electricity. Europe is one of the 12 regions. Details on the regional and sectoral disaggregation can be found in supplementary material. The model is calibrated on the 2001 base year by modifying the input-output tables provided by the GTAP- 6 dataset (Dimaranan and McDougall, 2006) to make them fully compatible with 2001 IEA energy balances (in Mtoe) and data on passenger mobility (in passenger-km) from Schafer and Victor (2000). The model simulates future trajectories through the recursive succession of static equilibria and dynamic modules with yearly steps.

The main exogenous assumptions are increased demography and labor productivity, the maximum potentials of technologies (renewable, nuclear, CCS, electrical vehicles, etc.), with learning rates decreasing the cost of technologies, fossil fuel reserves, the parameters of the functions representing energyefficiency in end uses.

\section{The scenario database}

In the long term, high uncertainty surrounds population growth, the growth and structure of the economy, energy markets, low-carbon technologies, and even energy efficiency. Following the methodology proposed by Rozenberg et al. (2014), we constructed a database of scenarios combining hypotheses on a large number of model parameters. This allowed us to consider many different types of uncertainty drivers simultaneously. ${ }^{17}$

Here we briefly present the six different drivers we analyzed and the alternatives we considered. A full description of the choice of parameters is given in the Appendix. For each parameter, the alternatives considered are contrasted, but no extreme assumption is included.

\section{- Availability of different types of low carbon technologies:}

\footnotetext{
${ }^{16}$ A full description of the model is available at http://www.imaclim.centre-cired.fr/lMG/pdf/imaclim_v1.0.pdf. Details on the model structure and results with respect to various aspects (energy technologies, energy efficiency, fossil fuels, macro economy) can be found in the publications listed in supplementary material.

17 This method is frequently used to investigate the uncertainty space in integrated assessment models. Of course, only a portion of the full uncertainty space is investigated, and the results depend on the choices of the sets of parameters to vary and of the alternative values tested. Obviously, the impact of an uncertain driver on the results depends on the numerical assumptions behind each state of the driver. This limitation is inherent to our methodology, like in all sensitivity analyses, but cannot be avoided when accounting for uncertainty in a large number of model input parameters.
} 
The availability and diffusion of some low carbon technologies will strongly impact the future of energy systems. We considered three different groups:

- Low carbon power generation technologies (nuclear energy and renewable resources); ${ }^{18}$

- Carbon capture and storage (CCS) technologies;

- Low carbon end use technologies in the transport and residential sectors (electric and hybrid vehicles, efficient buildings and household equipment).

For each group of low carbon technologies, we built two sets of assumptions for parameters describing their costs, the learning rates on investment costs and maximum market shares over the entire simulation period. One alternative corresponds to limited availability (high cost and low potential market share) of the technology concerned; the other corresponds to high availability (low cost and high potential market share).

\section{- Induced energy efficiency (IEE):}

Energy efficiency in end use sectors (agriculture, industry, construction and services) is endogenous and is driven by energy prices. ${ }^{19}$ We introduced two alternatives for the parameters to describe its maximum annual improvement in the leading country and the catch-up speed of the other countries: one fast IEE and one slow IEE.

\section{- Fossil fuel resources and markets:}

This set describes assumptions concerning oil, gas and coal resources and markets. These parameters include: (1) the amount of ultimately recoverable resources; (2) the amount of investment by Middle Eastern countries required to sustain oil production at the scale of existing oil fields and to explore new fields; (3) inertia in the development of non-conventional production; (4) the indexation (or de-indexation) of gas prices to oil prices; and (5) changes in coal prices in response to fluctuations in demand. One assumption corresponds to relatively abundant fossil fuels, the other to relatively scarce fossil fuels.

\section{- Economic growth:}

In the Imaclim-R model, economic growth is endogenous but is driven by exogenous trends of population growth and labor productivity. We built three alternative combinations of population growth and labor productivity trends that correspond to the SSP (Shared socioeconomic pathways) 1, 2 and 3 . SSPs are the new generation of socioeconomic scenarios for climate change research (O'Neill et al., 2014). SSP1 can be described as a scenario with low population and high productivity growth, while SSP3 is a scenario with high population and slow productivity growth and SSP2 lies between the two ${ }^{20}$.

Combining those assumptions gave $96\left(3 \times 2^{5}\right)$ baseline scenarios with different trajectories of $\mathrm{CO}_{2}$ emissions during the course of the century. In each of these scenarios, we added an exogenous constraint on global $\mathrm{CO}_{2}$ emission trajectories leading to 96 climate policy scenarios. Figure 1 shows global emissions over the $21^{\text {st }}$ century in the 96 simulations in the absence of a climate policy (each black line

\footnotetext{
18 In the "low" assumption, it is assumed that the new generation of nuclear energy is not available at all.

19 See Bibas et al. (2014) for a detailed description of how energy efficiency is modelled and how it impacts the model.

20 The populations and GDP quantifications of SSPs are available on a IIASA database:

https://secure.iiasa.ac.at/web-apps/ene/SspDb
} 
corresponds to one scenario) and the cap on global emissions when climate policies are implemented (red line). ${ }^{21}$

Figure 1: Global emissions over the century in the 96 simulations with no climate policy (each black line corresponds to one scenario) and the cap on global emissions when climate policies are implemented (red line)

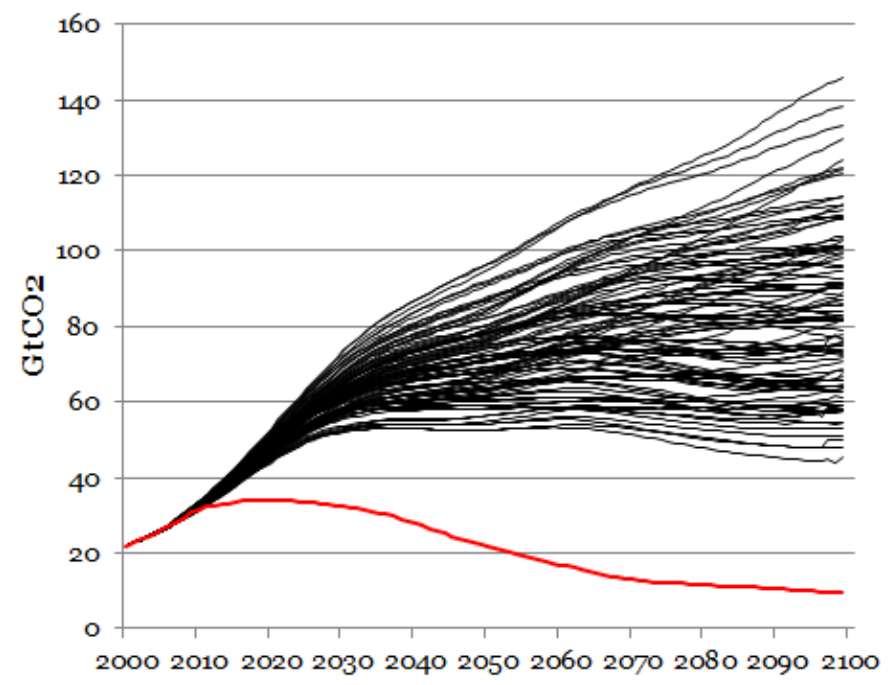

The trajectory of emissions was chosen to be consistent with the stabilization of $\mathrm{CO}_{2}$ concentrations in the atmosphere at 550 ppm $\mathrm{CO}_{2}$-eq: global emissions peak in 2020, and are reduced by $30 \%$ and $75 \%$ with respect to the 2010 level in 2050 and 2100, respectively. As a working hypothesis, we assume an international climate regime imposing a global carbon tax (or a corresponding global cap-and-trade system) designed to reach the target emission trajectory from 2011.22 The tax level is determined endogenously and changed each year to respect the global emissions constraint. Although extreme, this assumption has the advantage of avoiding the need to define an inevitably arbitrary share of the reduction in emissions among countries. Like in Guivarch et al. (2015), we restrict our analysis to the period up to 2075 , beyond which certain factors, notably technologies, are very uncertain. ${ }^{23}$

\footnotetext{
21 The model is calibrated in 2001, which is therefore the starting year of the modeling horizon. In the reference scenarios, $\mathrm{CO}_{2}$ emissions over 2001-2010 vary slightly between the scenarios. But the variation is small, less than $5 \%$. For instance, this variation is smaller than the uncertainty in $\mathrm{CO}_{2}$ emissions measurement. See for instance Le Quéré et al. (2015) who report, for the last decade available (2005-2014), $\mathrm{CO}_{2}$ emissions equal to $9 \pm 0.5 \mathrm{GtC} / \mathrm{yr}$, where $0.5 \mathrm{GtC} / \mathrm{yr}$ represents one standard deviation of the measured emissions.

22 This working hypothesis, a mitigation policy starting in 2011, is not realistic, just as an international climate regime leading to a global carbon price is not to expect, at least on the short-term. However, since the Copenhagen Agreement, we are also not anymore in a "reference" scenario as some mitigation measures in some regions of the world are already implemented, including non-Annex I countries.

${ }^{23}$ We limit the period to 2075 because a few scenarios (12 on 96) of the database do not run until 2100 (but run beyond 2075). If we had chosen to keep only scenarios running until 2100, we would have lost the scenarios based on sets of "less favorable" assumptions in terms of $\mathrm{CO}_{2}$-emission reductions. We think that it is important to keep these scenarios for our analysis.
} 


\section{Analysis of the indicators}

Our aim was to identify the determinants of energy systems that play a crucial role in the evolution of energy security in a low carbon world. Guivarch et al. (2015) showed that the effect of climate policies on energy security can differ significantly depending on the indicator or the time horizon considered. In the present paper, the first stage of the analysis was to evaluate the robustness or uncertainty of the simulated trajectories of the energy security indicators, with respect to the uncertainty of the driving forces. To this end, we calculated the relative standard deviation at each date, defined as the ratio of the standard deviation to the (arithmetic) mean value across all scenarios. This statistical tool reveals the extent of variability of a result in relation to its mean value.

The second stage of the analysis was to identify the factors that contribute most to this variability. The contributions of each uncertainty driver over time result from an analysis of variance, ANOVA, based on the partitioning of the sum of squares in a linear regression. The total sum of squares (i.e. the variance of the results, multiplied by the number of scenarios minus one) can be partitioned into the explained sum of squares linked to each uncertainty driver and the residual sum of squares (which corresponds to the non-linear interactions between drivers). This partitioning of the sum of squares is computed each year for the ensemble of scenarios. It gives the fraction of variance explained by each uncertainty driver at each time step.

\section{Results}

Here we present results for Europe, one of the regions represented in the Imaclim-R model. First, we describe the evolution of all the indicators over the course of the present century. In the first line of Figures 2, 3 and 4 each line represents one scenario, i.e. one combination of the different assumptions under consideration. The dispersion of each indicator was evaluated by the relative standard deviation (RSD). This analysis revealed significant differences in the values of some indicators depending on the future considered. An indicator even improves over time in some scenarios but deteriorate in other scenarios. Second, we focused on the most dispersed indicators for which more than one driver explains the variability. An analysis of variance was conducted to identify the uncertainty drivers that contribute the most to this dispersion. We then discuss the results obtained.

\subsection{The evolution and dispersion of the indicators}

Here we analyze the different sets of indicators that highlight a specific energy security perspective. Figure 2 presents the indicators of the sovereignty perspective. All the indicators were calculated such that an increase (respectively a decrease) in their value indicates a worsening (respectively an improvement) in the dimension of energy security they measure. The RSD allowed us to assess whether an indicator varied a lot, or a little in the different scenarios. ${ }^{24}$ In other words, it evaluated the degree of uncertainty of the indicator across the scenarios considered. Variability can also change over time.

${ }^{24}$ All the figures presenting the RSD have the same scale. 
Figure 2: Evolution and dispersion of the indicators of the sovereignty perspective

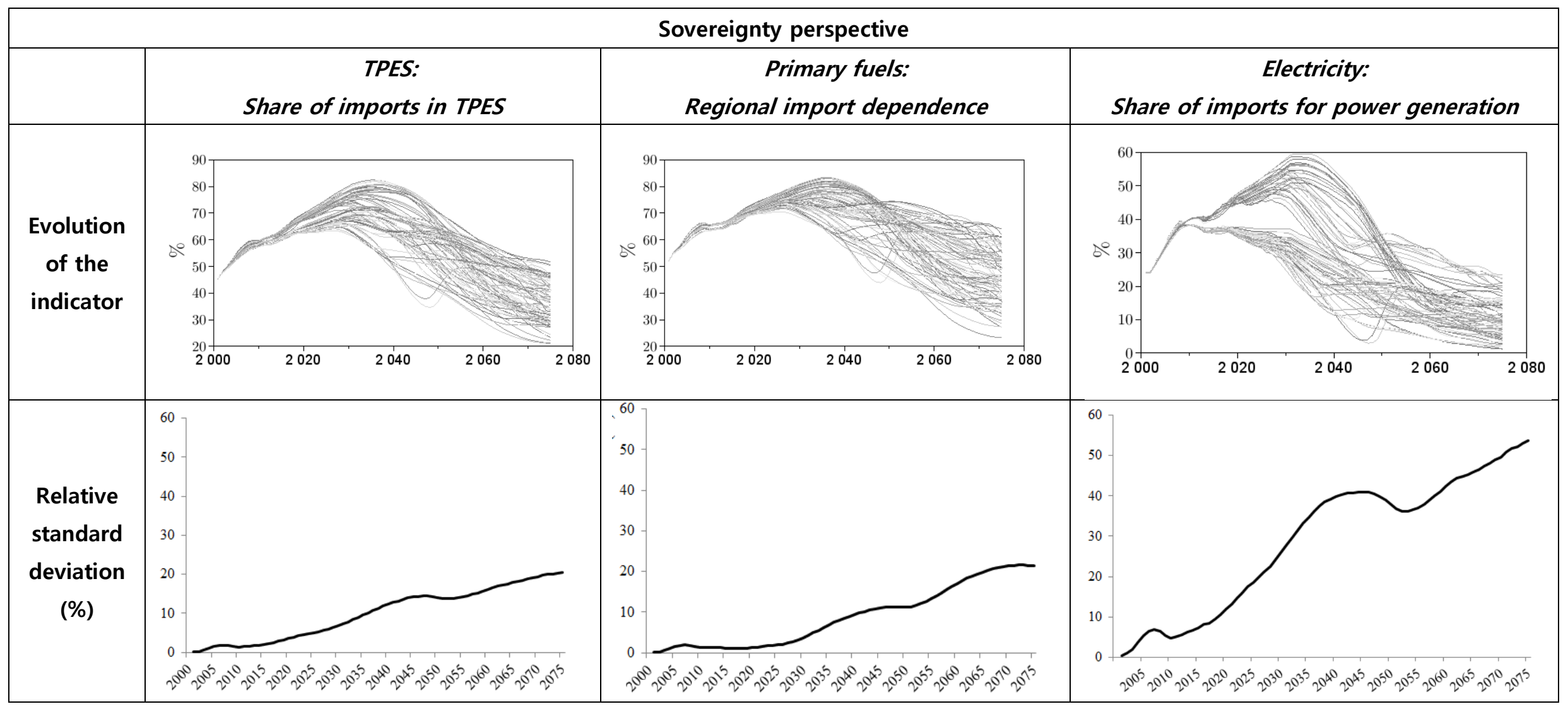

13 
The sovereignty perspective refers to threats posed by external actors and the exposure of a region/ country to these threats (Cherp and Jewell, 2011). This is apprehended by different indicators based on the share of imports used for the functioning of the three energy systems analyzed. Figure 2 shows that the indicators of the sovereignty follow similar trends. This result is not surprising because these three indicators are related since all have some links to imports of fossil fuels. However, the indicator for electricity exhibits higher variability than the two others.

For TPES and primary fuels, in all scenarios there is a first phase of worsening of the indicator, then a trend reversal between 2025 and 2035, followed by an improvement of the indicator in the long term. The date of the trend reversal and the speed of the subsequent improvement vary across scenarios. The shortterm worsening is due to carbon pricing triggering substitutions away from (mainly domestic) coal towards (mainly imported) gas. The long-term improvement is due to higher market penetration of renewable energies, as well as by the penetration of CCS technologies that enable the use of domestic coal with low emissions. These results reveal that the implementation of ambitious climate policies in Europe initially worsens these indicators compared to 2000, irrespective of the combination of assumptions envisaged. After around 2040, the indicators improve, with less reliance on imports in some scenarios, whereas the indicators are still worse in other scenarios. Moreover, in a few scenarios, the dependence on imports remains higher than in 2000 until the end of the study period, 2075. As shown by the RSD, the spread across scenarios increases over time. At the end of the simulation period, the ratio of the standard deviation to the mean is around $20 \%$ for both the systems.

For the electricity system, two groups of scenarios can be distinguished. One group follows the same trend as that described for TPES and primary fuels. The other group is not subject to the first phase of worsening of the indicator, but follows a relatively flat, or slightly improved, trajectory until 2030. The intensity of the use of renewable energies in the medium term explains this difference: when the use of renewable energies is high, market penetration by gas powered plants limits associated imports of gas. The improvement of this indicator happens earlier than for the other systems studied. As early as 2030, in some scenarios, the reliance on imports to produce electricity in Europe is reduced, compared to the situation at the beginning of the century. Moreover, at the end of the simulation period, the indicator is improved in all the scenarios. Like the other systems, except for a short period around 2050, the variability of the indicator across scenarios increases over time. But the RSD of the simulated values is higher for this indicator than in the two other systems. Moreover, this energy carrier should play an increasing importance from the medium-term. This confirms the importance of understanding which drivers explain this variability.

Figure 3 presents the evolution and dispersion of the indicators of the robustness perspective. 
Figure 3: Evolution and dispersion of the indicators of the robustness perspective




The robustness perspective refers to threats related to technical factors, such as scarcity of resources, aging of infrastructure or technical failures. The indicators selected to apprehend this perspective deal with the availability of the oil resource compared to production, and a technology used to produce electricity but regularly questioned, in particular given the risk of major accidents.

Figure 3 shows that the ratio of oil production to oil resources worsens continuously over time until around 2060 in all the scenarios. However, the speed of degradation varies across the scenarios. The indicator remains relatively flat in some scenarios, but increases substantially in others. This reveals that, although ambitious, the climate policies will not prevent the worsening of the ratio of oil production to oil resources for several decades. This indicator is not specific to Europe; the result applies to the whole world. After 2060, there is an improvement in some scenarios but the situation remains worse than at the beginning of the century. The improvement happens because, in some scenarios, extraction of oil is sufficiently slowed down by climate policy to counter-balance the effect of depletion. As shown by the RSD, the spread across scenarios increases over time. At the end of the simulation period, the ratio of the standard deviation to the mean is around $30 \%$.

For electricity, two groups of scenarios can be distinguished, even though the indicator is degraded in both (i.e. the share of intermittent renewable increases over time in both). These two groups correspond to the two alternatives on the availability of low-carbon power generation technologies. In the "low" alternative, the penetration of renewable energies is slow and takes-off only after 2030, whereas in the "high" alternative, the penetration of renewable energies is faster and they reach roughly $50 \%$ of electricity production in 2040.

Figure 4 presents the evolution and dispersion of the indicators of the resilience perspective. 
Figure 4: Evolution and dispersion of the indicators of the resilience perspective



Note: The values for the two Herfindahl-Hirschmann indexes measuring the concentration of oil markets and the concentration of primary sources for electricity production cannot be directly compared, because the values of the index depends on the number of categories in the aggregation (12 regions for the index measuring the concentration of oil markets, 7 categories of primary sources for the index measuring the concentration of primary sources for electricity production). 
From the resilience perspective, the future is considered to be unpredictable. This future uncertainty may be related to markets, technologies and societies. The indicators aim to characterize the exposure, adaptability, or diversity of energy systems with respect to different known and unknown threats (Cherp and Jewel, 2011). Figure 4 shows that the trends of the indicators of the resilience perspective vary between vulnerable systems and among the scenarios.

For TPES, the energy intensity of GDP is improved over time in all the scenarios. Carbon pricing accelerates the historical trend of a decrease in energy intensity over time. The speed of the improvement varies between scenarios, and ranges from a $1.6 \% / \mathrm{yr}$ to a $2.7 \% / \mathrm{yr}$ decrease in energy intensity between 2015 and 2075. The RSD increases over time to reach almost $25 \%$ at the end of the study period.

Concerning primary fuels, the concentration of oil markets follows approximately the same trajectory in most scenarios: first, the concentration increases until approximately 2030, then decreases for two to three decades before beginning another long term increase. The short-term increase is due to carbon pricing which excludes unconventional oil producers from the market, after which the markets are diversified, and partly because CCS allows some unconventional oil producers to enter the market, partly because depletion of conventional resources decreases the market shares of conventional producers. In the longterm, the oil markets again become concentrated because of the depletion of conventional resources. The trajectories are very similar in all the scenarios, and the RSD remains below $4 \%$ throughout the study period.

The evolution of the diversity of primary energy sources used in electricity production differs considerably among the scenarios. In some, the indicator improves from 2011 on, whereas in others it deteriorates. These differences remain high over time. The RSD reaches a peak of approximately 35\% around 2040. From 2060 on, the trajectories are less chaotic but dispersion among the scenarios remains high.

To summarize, the evolution of energy security dimensions in a low-carbon world are varied and complex. The conclusion depends on the indicator examined but also on the time horizon considered. Moreover, the dispersion of some indicators is substantially higher than that of others. In the following, we analyze which uncertainty drivers explain this dispersion.

\subsection{Contribution of the different determinants}

Our objective was to identify the main factors behind the dispersion of the indicators. We focused on those characterized by the highest variability. Consequently we excluded the indicator of the resilience perspective for primary fuels whose RSD peaked at $4 \%$.

A first group of indicators was characterized by some variation across the scenarios, but this variation is almost entirely explained by a single assumption. Figure 5 shows the result of the ANOVA for the ratio of oil production to oil resources and the share of renewable energies in electricity production (excluding biomass and hydro). Both the indicators are related to the robustness perspective. 
Figure 5: Analysis of variance

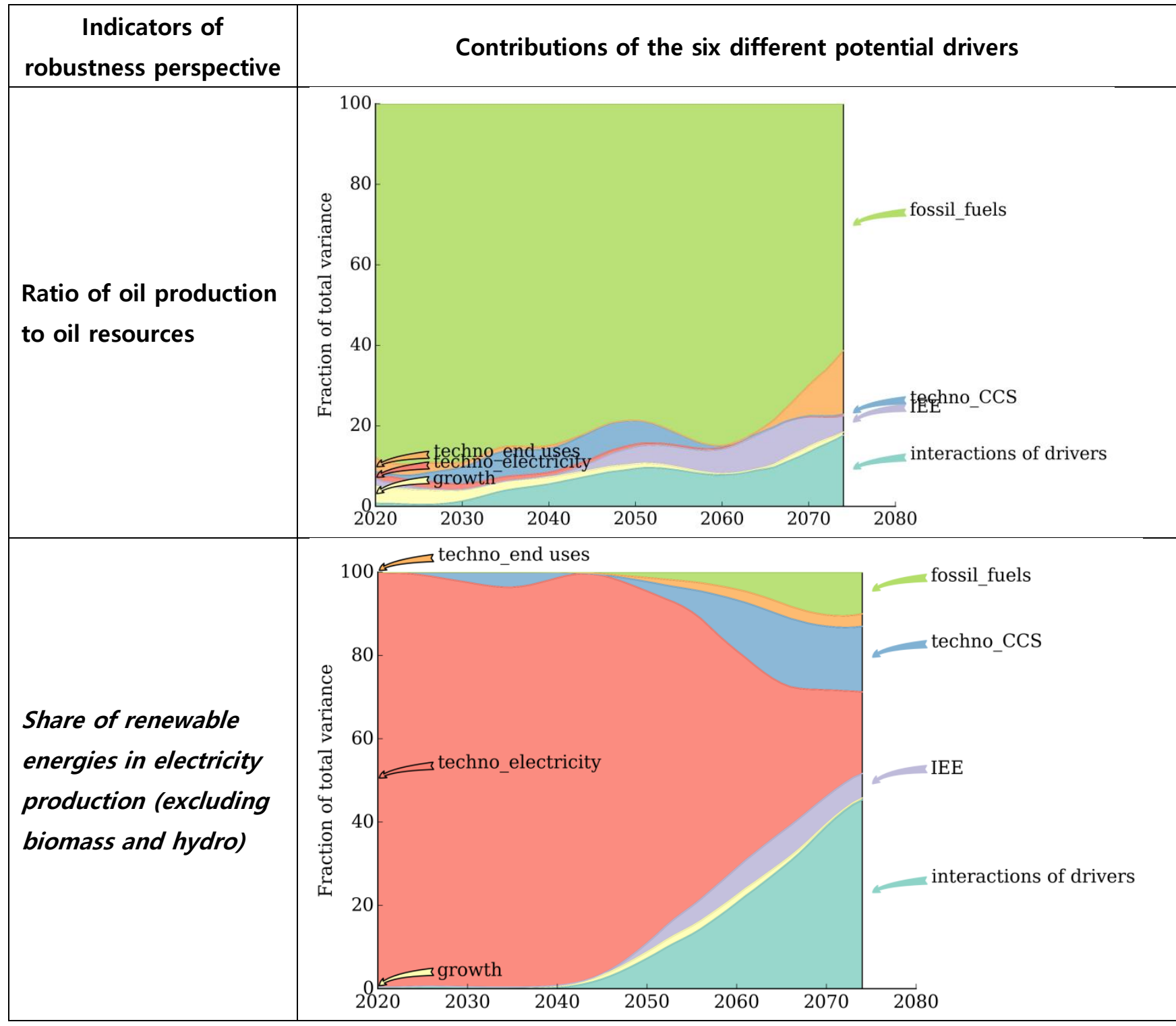

Notes: The graphs show the contributions of each driver to the total uncertainty of the energy security indicator over time. A different color is used for each type of driver: red for low carbon power generation technologies, blue for CCS technologies, orange for low carbon end-use technologies in the transport and residential sectors; purple for induced energy efficiency (IEE), green for fossil fuel resources and markets, and yellow for economic growth.

The dispersion of the ratio of oil production to resources is mainly explained by the assumption concerning the fossil fuel resources and markets. Logically, the indicators worsen over time in the scenarios with a "low" assumption for fossil fuels, but remain stable in the scenarios with the alternative assumption. In the second case, the climate policies reduce the production required to satisfy world demand.

Concerning the share of renewable energies in the production of electricity, dispersion is mainly due to the assumption concerning power generation technologies. Logically, the scenarios based on the "high" assumption, characterized by low cost and a high potential market share for renewable energies, indicate greater capacities. Renewable energies improve the energy independence in Europe, but the inclusion of 
large amounts of intermittent energy makes managing the electricity network more complex. From the robustness perspective, energy security is thus degraded.

Concerning the remaining indicators, we now analyze the factors that contribute to the variations among the scenarios in more detail. Indicators of the robustness perspective are no longer included. Figures 6 and 7 present the contributions of each driver to the total uncertainty surrounding the energy security indicator (second column) over time. The evolution of the indicator is shown again to show the "direction" of the effect of each determinant. Only the three drivers that contribute most to the variance of the indicator are included. The solid line represents the average of the indicator across the subset of scenarios based on the "high" assumption; the dashed line represents the average of the indicator across the subset of scenarios based on the "low" assumption. Table 2 is a reminder of the meaning of the "low" and "high" assumptions with their corresponding color in Figures 6 and 7.

Table 2: The "low" and "high" assumptions for the six drivers considered

\begin{tabular}{|c|c|c|c|c|}
\hline \multirow{2}{*}{ Determinants } & \multicolumn{4}{|c|}{ Assumptions and corresponding color } \\
\hline & Low & Color code & High & Color code \\
\hline $\begin{array}{l}\text { Power } \\
\text { generation } \\
\text { technologies }\end{array}$ & $\begin{array}{l}\text { Low availability } \\
\text { Slow learning }\end{array}$ & Dashed red & $\begin{array}{l}\text { High availability } \\
\text { Fast learning }\end{array}$ & Solid red \\
\hline $\begin{array}{l}\text { Carbon capture } \\
\text { and } \\
\text { sequestration }\end{array}$ & $\begin{array}{l}\text { Low availability } \\
\text { Slow learning }\end{array}$ & Dashed blue & $\begin{array}{l}\text { High availability } \\
\text { Fast learning }\end{array}$ & Solid blue \\
\hline $\begin{array}{l}\text { End-use } \\
\text { technologies }\end{array}$ & $\begin{array}{l}\text { Low availability } \\
\text { Slow learning }\end{array}$ & $\begin{array}{l}\text { Dashed } \\
\text { orange }\end{array}$ & $\begin{array}{l}\text { High availability } \\
\text { Fast learning }\end{array}$ & Solid orange \\
\hline IEE & Slow & Dashed purple & Fast learning & Solid purple \\
\hline $\begin{array}{l}\text { Fossil fuels } \\
\text { resources and } \\
\text { markets }\end{array}$ & Scarce/expensive & Dashed green & Abundant /cheap & Solid green \\
\hline $\begin{array}{l}\text { Economic } \\
\text { growth }\end{array}$ & $\begin{array}{l}\text { Slow leader } \\
\text { productivity } \\
\text { growth } \\
\text { Slow } \\
\text { productivity } \\
\text { catch-up }\end{array}$ & Dashed yellow & $\begin{array}{l}\text { Rapid leader } \\
\text { productivity growth } \\
\text { Rapid productivity } \\
\text { catch-up }\end{array}$ & Solid yellow \\
\hline
\end{tabular}


Figure 6: Analysis of the dispersion of the indicators of the sovereignty perspective

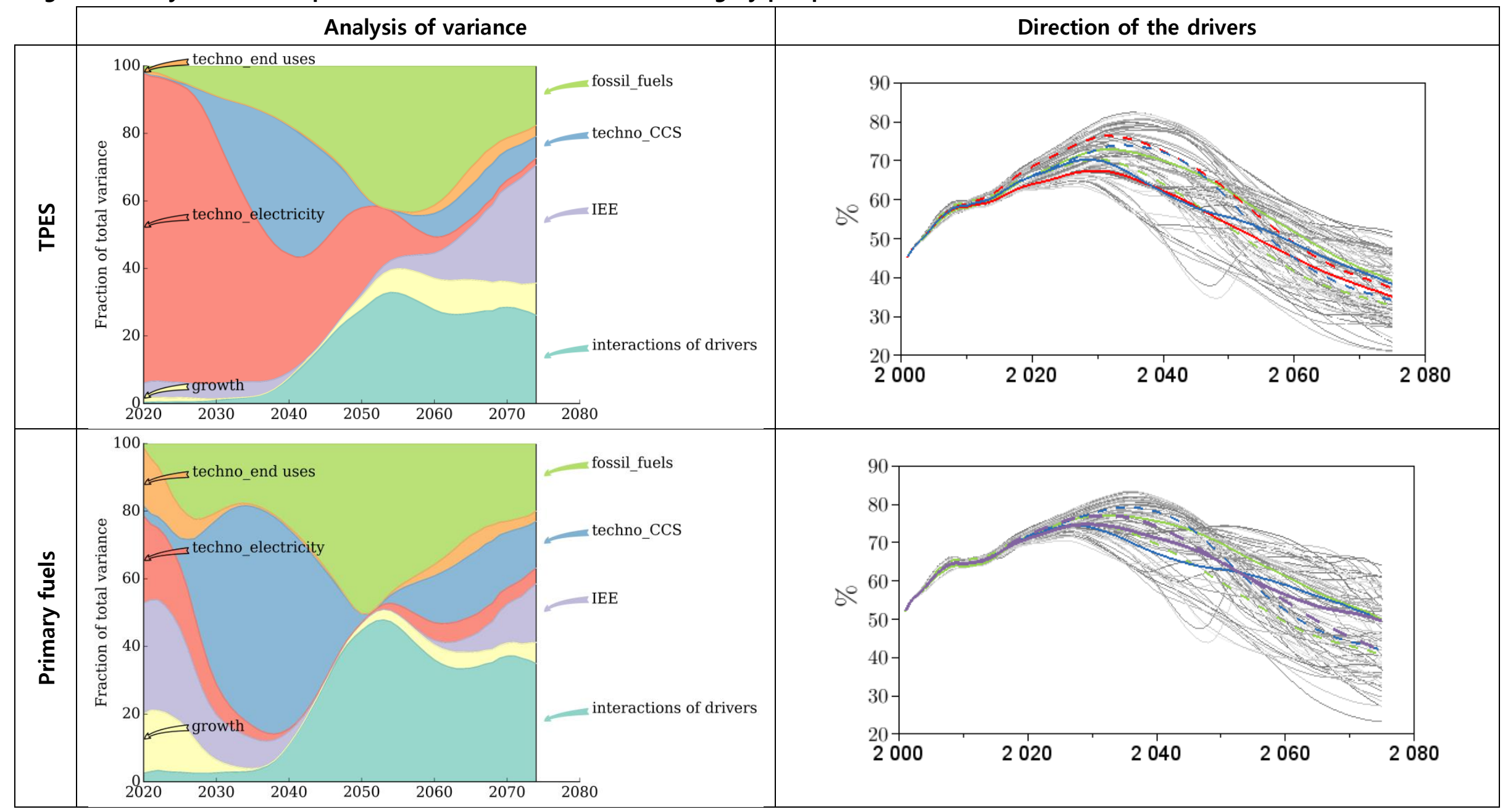






Note: The same color code is used as in fig. 5 . 
Figure 6 shows the results of the three indicators of the sovereignty perspective. They reveal that the three indicators share two main drivers. Indeed, the assumptions concerning CCS technologies and fossil fuels have a significant effect on all three indicators. The third determinant is the assumption concerning power generation technologies for the indicators on TPES and electricity, whereas the determinant is the assumption concerning IEE for the indicator on primary fuels. Nevertheless, the evolution of these drivers over the century differs among the indicators. For the share of imports in TPES and in power generation, the assumption concerning power generation technologies explains a large proportion of the variation among the scenarios. This driver is particularly important in the short and medium term, but its importance declines in the long term, especially for the share of imports in TPES. For both indicators, the "high" assumption leads to a significant improvement in energy security. The explanation for this result is that "high" availability of low-carbon power generation technologies leads to faster penetration of renewable energies, which limits the imports of gas and diversifies the power generation mix. From around 2050 on, this assumption explains the dispersion of the results for the share of imports in TPES to a lesser extent, whereas the assumptions concerning fossil fuels and IEE play a bigger role.

The assumption concerning CCS technologies is also an important driver of the uncertainty in the results of the two previous energy systems but also of primary fuels. Nevertheless, the "direction" of its impact varies over time: around 2050, the blue dashed and solid lines intersect. In the short and medium term, a "high" assumption of CCS enables a lower share of imports in all the energy systems studied, because it uses relatively more (mainly domestic) coal and limits the penetration of gas and associated imports. In the long term, the "high" assumption concerning CCS allows more fossil fuel-powered generation to remain in the electricity generation mix, which has a negative impact on the share of imports.

Not surprisingly, the assumption concerning fossil fuels explains a large proportion of the dispersion of the results of the sovereignty perspective indicators, especially in the long term. For the three systems, (TPES, primary fuels and electricity), the "high" availability of fossil fuels has a negative effect: in this case gas prices are lower, which leads to higher imports of gas and more gas in the power generation mix.

The last significant determinant of the primary fuels indicators is the assumption concerning IEE, which plays a role especially in the short term. After 2040, this assumption is no longer discriminating across the scenarios. After 2065, the assumption again plays a role, but less important than at the beginning of the century. The "high" assumption concerning IEE leads to scenarios with lower European reliance on imports because higher efficiency limits the overall energy demand, including for primary fuels.

In the long term, interactions between individual uncertainty drivers explain a large proportion (up to $30 \%$ or $40 \%$ ), of the variance of the indicators of the sovereignty perspective. 
Figure 7: Analysis of the dispersion of the indicators of the resilience perspective

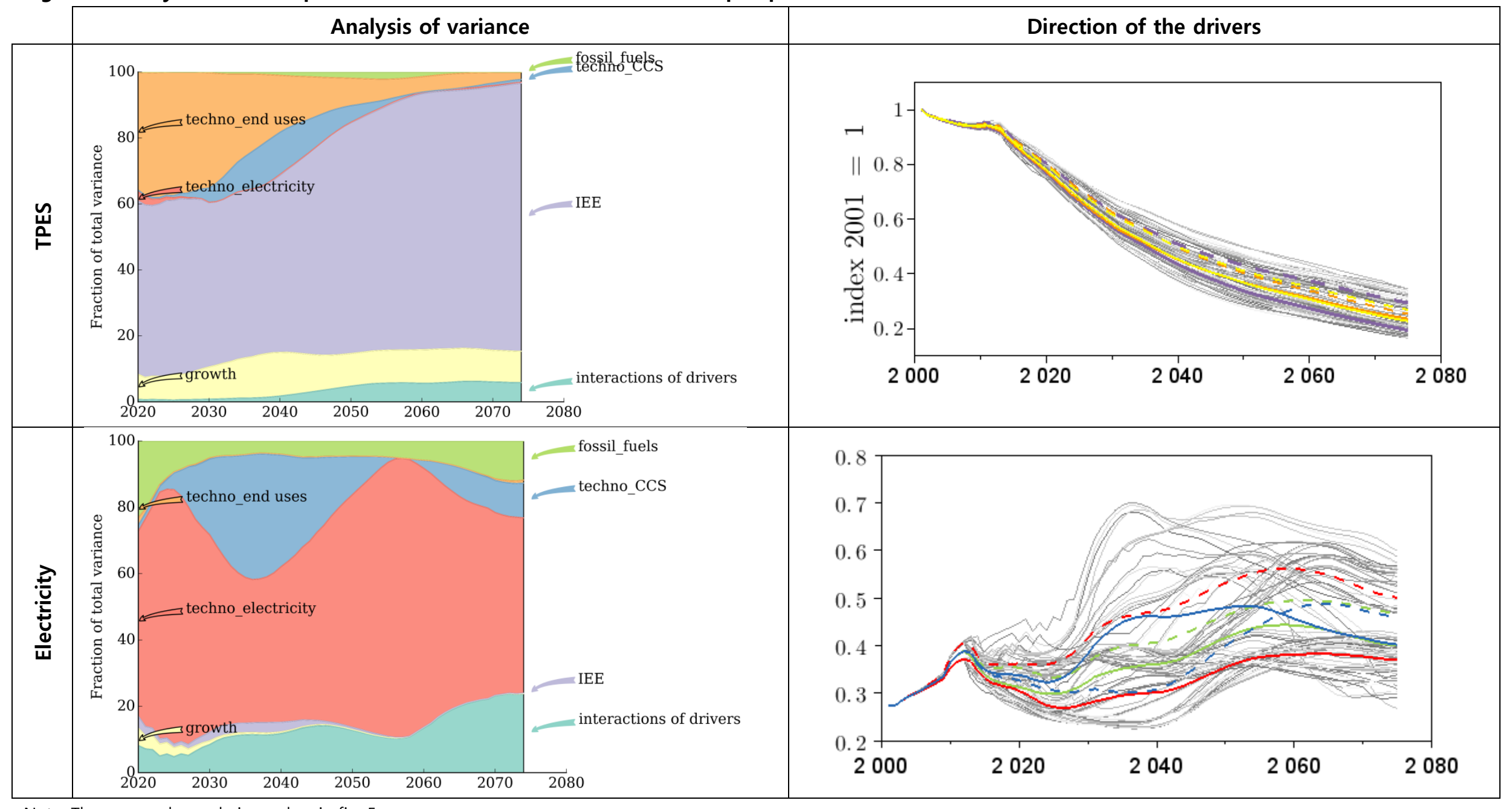

Note: The same color code is used as in fig. 5 . 
Figure 7 gives the results for two indicators from the resilience perspective. Unlike the sovereignty perspective, the two indicators share no driver to explain their dispersion. Indeed, the assumptions concerning IEE, end use technologies and economic growth are the main drivers of the uncertainty of the concentration of primary energies in power generation, whereas the assumptions concerning power generation technologies, CCS technologies and fossil fuels contribute the most to variability of energy intensity across the scenarios.

The assumption concerning IEE is the main uncertainty driver of the energy intensity of GDP. This discriminatory effect continues to the end of the century. The "high" assumption leads to rapid improvement of energy efficiency and thus significantly decreases energy consumption in the region. In the long term, this assumption also becomes important for the share of imports in TPES, an indicator of the sovereignty perspective, because higher efficiency limits overall energy demand, which can then be more easily satisfied with domestic resources.

The assumption concerning end use technologies is important for the energy intensity of GDP in the short term. Logically, the "high" assumption reduces energy intensity faster. ${ }^{25}$ The share of the variation across the scenarios is significantly due to end use technologies, especially in the short term.

Although more modest, the assumption concerning economic growth also explains some of the variance in energy intensity. Although small, the discriminatory effect lasts throughoutthe period. Greater economic growth improves the energy intensity of GDP. This is because faster growth leads to faster capital turnover and hence more rapid improvement in energy intensity.

The dispersion of the resilience indicator for the electricity system is explained by completely different drivers. Concerning the concentration of the power generation mix, the assumptions that play a distinguishing role are the same as for the sovereignty indicators for TPES and electricity, but the direction of some assumptions may nevertheless differ.

The assumption concerning power generation technologies plays the most important role in explaining the dispersion among the scenarios over the course of the century. This differs from the result concerning the share of imports in TPES and in power generation, for which the assumption shifts the evolution of the indictors especially in the short and medium terms. Here again, the "high" availability of low-carbon power generation technologies leads to faster penetration of renewables, which limits the imports of gas and diversifies the power generation mix.

The assumption concerning CCS technologies is a significant driver of the variation across the scenarios but there is a major difference in the results compared to the sovereignty indicators. Indeed, for the concentration of the power generation mix, the "high" assumption on CCS has a negative impact in the short and medium term because it limits the penetration of renewable energies, thus limiting the diversification of the mix. In the long term, the "high" assumption concerning CCS becomes positive for

\footnotetext{
${ }^{25}$ Note that, in the long term, "high" end-use technologies can have a negative effect on the share of imports for power generation, an indicator of sovereignty, because they enable to higher penetration of electrified vehicles thereby increasing the demand for electricity, which is met by power generation technologies that require imports of fuel. This result could differ if "smart-grid" options were included in the modeling framework.
} 
the diversity of the mix (i.e. it decreases the concentration of the power generation mix), because it allows more fossil fuel-powered generation to remain in the mix.

Lastly, the assumption concerning fossil fuels explains a rather modest proportion of the dispersion of the results for the concentration of the power generation mix. The assumption is most discriminating in the short term. The effect of "high" availability of fossil fuels is negative, because it reduces the cost of generation of fossil fuels (including with CCS) and thus limits the penetration of renewable energies that diversify the generation mix.

\section{Discussion and conclusion}

This analysis focused on Europe advances our understanding of the evolution of energy security in a low-carbon world. We identified the uncertainty drivers that explain the dispersion of the energy security indicators. As a result, we were able to identify levers that could limit the degradation of energy security if ambitious climate policies are implemented.

Our results show that the evolution of some indicators can be highly contrasted across the scenarios and over the course of the present century. The indicators for the electricity system exhibited the highest dispersion. Particular attention should be paid to this energy carrier so as not to damage European energy security too much when implementing significant reductions in $\mathrm{CO}_{2}$ emissions. Our results show that several uncertainty drivers play a crucial role in the evolution of these indicators. Logically, the cost and availability of the low carbon power generation technologies have a major effect on the dynamics of the indicators. If the "low" assumption concerning these technologies turns out to be true, European reliance on imported fuels for power generation and the concentration of primary energy sources in power generation would deteriorate significantly and rapidly, whereas the robustness of the system would be improved. Although less important, the cost and availability of the CCS technologies also affect the evolution of the indicators of the electricity system, but this driver plays a different role depending on the indicator concerned. If the "high" assumption on these technologies turns out to be true, the sovereignty of the system would be significantly improved, whereas its resilience would be degraded during the first half of the century. Indeed, strong diffusion of the CCS technology would reduce the share of imports thanks to increased use of coal, but would limit the penetration of renewables. In the long term, the effect would be reversed. This last result reveals a possible contradiction between the deployment of CCS technologies and that of renewables.

Concerning the other energy systems, we also found significant, but less, dispersion of the indicators. The results for TPES are the most interesting. The uncertainty drivers that contribute strongly to the variance of the results for sovereignty are the same as those for the electricity system. On the other hand, the resilience of TPES depends on completely different drivers. The one that contributes the most is induced energy efficiency.

Finally, the paper shows that the European double target of significantly decreasing $\mathrm{CO}_{2}$ emissions and increasing the security of the supply of energy may be difficult to reach. Nevertheless, some levers could facilitate the transition to a low-carbon society by improving energy security, or limiting its degradation. Indeed, our results emphasize the importance of policies in favor of low or zero carbon technologies in 
power generation, but also the differences in their contributions to the complete uncertainty of the indicators. Policies promoting energy efficiency also play a role but only in the resilience of TPES. These policies are thus important levers for mitigating the negative impacts of climate policies on energy security. It would be interesting to complete this analysis by focusing on specific uncertainty drivers and distinguishing between the different technologies (e.g. renewables and nuclear energy) or fossils fuels.

\section{References}

APERC, Asia Pacific Energy Research Centre, 2007. A Quest for Energy Security in the 21st Century: Resources and Constraints. Institute of Energy Economics, Japan.

Bibas, Ruben, Aurélie Méjean and Meriem Hamdi-Cherif, 2014. Energy efficiency policies and the timing of action: an assessment of climate mitigation costs. Technological Forecasting and Social Change, 90, Part A, 137-152.

Cherp, Aleh, and Jessica Jewell, 2011. The three perspectives on energy security: intellectual history, disciplinary roots and the potential for integration. Current Opinion in Environmental Sustainability, 3 (4), 202-212.

Cherp, Aleh, Adenikinju Adeola, Goldthau Andreas, Hernandez Francisco, Hughes Larry, Jansen Jaap C., Jewell Jessica, Olshanskaya Marina, de Oliveira Ricardo Soares, Sovacool Benjamin K., and Vakulenko Sergey, 2012. Energy and security. In: Global Energy Assessment: Toward a More Sustainable Future. Cambridge University Press, Cambridge, UK and New York, NY, USA and the International Institute for Applied Systems Analysis, Cambridge University Press, Laxenburg, Austria, pp. 325-383 (Chapter 5).

Cherp, Aleh, and Jessica Jewell. 2013. Energy security assessment framework and three case studies. In: International Handbook of Energy Security. Chapter 8, Edward Elgar Publishing, 146-73.

Cherp, Aleh, Jessica Jewell, Vadim Vinichenko, Nico Bauer and Enrica De Cian, 2013. Global Energy Security under Different Climate Policies, GDP Growth Rates and Fossil Resource Availabilities. Climatic Change, 121 (1), doi: 10.1007/s10584-013-0950-x.

Dimaranan, B., and R.A. McDougall, 2006. Global Trade, Assistance and Production: The GTAP 6 Data Base. Center for Global Trade Analysis, Purdue University, West Lafayette.

DNV GL, Imperial College and NERA Economic Consulting, 2014. Integration of Renewable Energy in Europe, Report foe European Commission 9011-700, June.

European Commission, 2011. Energy Roadmap 2050. Communication from the Commission to the European Parliament, the Council, the European Economic and Social Committee and the Committee of the Regions, $\operatorname{COM}(2011)$ 885/2.

Guivarch, Céline, Stéphanie Monjon, Julie Rozenberg and Adrien Vogt-Schilb, 2015. Would climate policy improve the European energy security?, Climate Change Economics, 6(2), May, doi: 10.1142/S2010007815500086.

Jewell, Jessica, A. Cherp, V. Vinichenko, N. Bauer, Tom Kober, and D. L. McCollum, 2013. Energy security of China, India, the EU and the US under long-term scenarios: results from six IAMs. Climate Change Economics, Vol. 04, No. 04, 1340011. 
Jewell, Jessica, Aleh Cherp and Keywan Riahi. 2014. Energy security under de-carbonization scenarios: An assessment framework and evaluation under different technology and policy choices. Energy Policy, 65, 743-760.

Krey, V., McCollum, D.L., Bottcher, H., Jewell, J., Johnson, N., Kolp, P. and Riahi, K., 2014. Chapter 6 Assessing transformation pathways. In: Climate Change 2014: Mitigation of Climate Change. IPCC Working Group III Contribution to AR5. Cambridge University Press.

Le Quéré, Corinne, R. Moriarty, R. M. Andrew, J. G. Canadell, S. Sitch, J. I. Korsbakken, P. Friedlingstein, et al. 2015. Global Carbon Budget 2015, Earth System Science Data, 7: 34996.

O'Neill, B. C., E. Kriegler, K. Riahi, K. Ebi, S. Hallegatte, T.R. Carter, R. Mathur and D.P. van Vuuren, 2014. A new scenario framework for climate change research: The concept of shared socioeconomic pathways. Climatic Change, 122(3), 387-400.

Quoc Hung Duong, Md Rakibuzzaman Shah, N. Mithulananthan, 2016. Technical Challenges, Security and Risk in Grid Integration of Renewable Energy, Smart Power Systems and Renewable Energy System Integration, Volume 57 of the series Studies in Systems, Decision and Control, 99-118.

Rozenberg, J., C. Guivarch, R. Lempert and S. Hallegatte, 2014. Building SSPs for climate policy analysis: a scenario elicitation methodology to map the space of possible future challenges to mitigation and adaptation. Climatic Change, 122 (3), 509-522.

Saltelli, A., 2002. Sensitivity analysis for importance assessment, Risk Analysis, 22(3), 579-90.

Schafer, A., and D.G. Victor, 2000. The future mobility of the world population. Transportation Research, Part A, 34 (3), 171-205.

Waisman, H., C. Guivarch, F. Grazi and J.-C. Hourcade, 2012. The Imaclim-R model: infrastructures, technical inertia and the costs of low carbon futures under imperfect foresight. Climatic Change, 114 (1), $101-120$.

Winzer, C., 2012. Conceptualizing energy security. Energy Policy, 46, 36-48. 


\section{Appendix - Description of the scenarios database}

A "low" or "high" assumption refers to different values for a set of parameters of the model. In this appendix, we detail the parameters on which a "low" or "high" assumption is based on. For each parameter, the alternatives considered are contrasted but no extreme assumption is integrated.

The alternatives for the parameters for growth drivers are based on SSPs (Shared Socioeconomic Pathways). The alternatives for technologies or fossil fuels resources and markets are based on discussions we had with experts from the sectors. The alternatives for maximum shares of the electrified vehicles and the CCS technologies are more contrasted than for the renewables, because the former are less mature technologies and therefore there is more uncertainty on their future development. The alternatives for energy efficiency are such that the mean energy intensity decrease over the modeling horizon for Europe in baseline scenarios with "high" energy efficiency is $1.9 \% / \mathrm{yr}$, whereas it is $1.5 \% / \mathrm{yr}$ in baseline scenarios with "low" energy efficiency. Those numbers lie on each side of the average decrease of $1.7 \% / y$ r observed for Europe between 1990 and 2012.

\section{A.1. Drivers of economic growth}

The natural growth rate of the economy defines the growth rate that the economy would follow if it produced a composite good at full employment, like in standard neoclassical models developed after Solow (1956). Equation 1 represents labor productivity growth through the decrease in unitary labor input $\mathrm{I}$ in each region $\mathrm{j}$ and at each time step $\mathrm{t}$.

$$
\dot{l}(t, j)=e^{-\frac{t}{\tau_{1}}} \cdot l\left(t_{0}, j\right)+\left(1-e^{-\frac{t}{\tau_{1}}}\right) \cdot\left[\frac{t}{\tau_{2}} \cdot(l(t, j)-l(t, \text { leader })+\dot{l}(t, \text { leader }))\right]
$$

In line with the SSP quantifications, we build assumptions combining hypotheses on population growth, on the leader productivity growth, and on catch-up speed for two groups of regions: high income and low income countries (see Tables 3 and 4).

Table 3: Parameters options for leader growth and high income population growth. Population data are available at https://secure.iiasa.ac.at/web-apps/ene/SspDb

\begin{tabular}{lllc}
\hline & Slow growth & Intermediate growth & Rapid growth \\
\hline Leader productivity growth & slow & medium & rapid \\
High income population growth & SSP3 & SSP2 & SSP1 \\
\hline
\end{tabular}

Table 4: Parameters options for low income catch-up speed and population growth. Population data are available at https://secure.iiasa.ac.at/web-apps/ene/SspDb

\begin{tabular}{lcccc}
\hline & Slow growth & Intermediate growth & Rapid growth \\
\hline $\begin{array}{l}\text { Low income catch up time }\left(\tau_{2} \text { in eq. 1, in }\right. \\
\text { years) }\end{array}$ & 300 & 200 & 150 \\
Low income population growth & SSP3 & SSP2 & SSP1 \\
\hline
\end{tabular}




\section{A.2. Availability of different types of low carbon technologies}

In the Imaclim-R model, technologies penetrate the markets according to their profitability, but are constrained by a maximum market share which follows a S-shaped curve (Grubler et al., 1999). This Sshaped curve is defined by three phases. First, there is a "bottleneck" phase during which the technology is a niche technology and has a maximum market share growing linearly from $0 \%$ at the start date to $5 \%$ of the defined maximum share (called "Maximum market share at the end of the maturation phase") at the end of the phase. Then, during the "growth" phase, the maximum market share of the technology grows linearly to $90 \%$ of the defined maximum share. Finally, during the "maturation" phase, the maximum market share of the technology grows linearly to $100 \%$ of the defined maximum share. We consider two alternatives for each group of technologies. The high availability assumption corresponds to an earlier start date (only for Carbon Capture and Storage), a higher maximum market share, and faster diffusion than under the low availability assumption. Moreover, for some new technologies, there is an endogenous learning mechanism: the cost of the technology is reduced with the cumulative investment in that technology. This mechanism is governed by a learning rate, and two alternative values are considered for this learning rate.

- Low carbon power generation technologies

The technologies considered are nuclear and renewable energies. In the low availability assumption it is assumed that the new generation of nuclear energy is not available at all. The parameters are described in Table 5.

- Carbon Capture and Storage (CCS)

The parameters of each alternative are listed in Table 5.

- Low carbon end-uses technologies

The technologies considered are electric and hybrid vehicles, efficient buildings and household equipment. The parameters for electric and hybrid vehicles are described in Table 5.

Table 5: Parameters options for low carbon power generation, CCS and electric and hybrid vehicles

\begin{tabular}{|c|c|c|c|c|c|c|c|}
\hline & & $\begin{array}{l}\text { Start } \\
\text { date }\end{array}$ & $\begin{array}{l}\text { Bottlenec } \\
\text { k phase } \\
\text { (years) }\end{array}$ & $\begin{array}{l}\text { Growth } \\
\text { phase } \\
\text { (years) }\end{array}$ & $\begin{array}{l}\text { Maturation } \\
\text { phase } \\
\text { (years) }\end{array}$ & $\begin{array}{l}\text { Maximum market } \\
\text { share at the end of } \\
\text { the maturation phase } \\
(\%)\end{array}$ & $\begin{array}{l}\text { Learning } \\
\text { rate }\end{array}$ \\
\hline \multirow{2}{*}{$\begin{array}{l}\text { Nuclear } \\
\text { (new } \\
\text { generation } \\
\text { ) }\end{array}$} & $\begin{array}{c}\text { High } \\
\text { availability }\end{array}$ & 2001 & 15 & 75 & 25 & 30 & \\
\hline & $\begin{array}{c}\text { Low } \\
\text { availability }\end{array}$ & & & & & 0 & \\
\hline \multirow{2}{*}{$\begin{array}{l}\text { Renewable } \\
\text { s }\end{array}$} & $\begin{array}{c}\text { High } \\
\text { availability }\end{array}$ & 2001 & 2 & 20 & 15 & 60 & 0.07 \\
\hline & $\begin{array}{c}\text { Low } \\
\text { availability }\end{array}$ & 2001 & 3 & 65 & 25 & 50 & 0.05 \\
\hline CCS & $\begin{array}{c}\text { High } \\
\text { availability }\end{array}$ & 2010 & 13 & 8 & 8 & 80 & 0.1 \\
\hline
\end{tabular}




\begin{tabular}{lccccccc}
\hline & $\begin{array}{c}\text { Low } \\
\text { availability }\end{array}$ & 2014 & 17 & 8 & 8 & 30 & 0.05 \\
\hline $\begin{array}{l}\text { Electric } \\
\text { and } \\
\text { hybrid } \\
\text { vehicles }\end{array}$ & $\begin{array}{c}\text { High } \\
\text { availability }\end{array}$ & 2010 & 6 & 40 & 16 & 80 & 0.2 \\
\cline { 2 - 7 } & Low & 2010 & 6 & 40 & 16 & 25 & 0.1 \\
\hline
\end{tabular}

In the residential sector, the buildings stock is divided into two types of buildings: "classical" buildings and very low energy buildings (that consume $50 \mathrm{kWh}$ per square meter and per year, $80 \%$ of which is electricity and $20 \%$ gas). The energy consumption of "classical" buildings is described by equation 2 . The penetration of very low energy buildings depends on its extra investment cost that decreases following a learning rate. The parameters are listed in Table 6.

Housing energy expenditure of "classical" buildings:

$$
H_{E x p}=\sum_{e}\left(\mu_{h}(t) \cdot \alpha_{m 2}^{e} \cdot b_{s t o c k} \cdot p F D_{e}\right)
$$

where $H_{E x p}$ is the total energy expenditure in housing, for each country; $\alpha_{m 2}^{e}$ is the energy consumption of buildings e per $\mathrm{m}^{2}$, in each country (exogenous trend calibrated on POLES: see LEPII-EPE (2006)); $\mu_{h}(t)$ is a multiplier coefficient at year $\mathrm{t} ; b_{\text {stock }}$ is the building stock in each country; $p F D_{e}$ is the price of final demand for energy e in each country (which takes all taxes, including the carbon tax, into account).

Table 6: Parameters options for residential buildings and household equipment

\begin{tabular}{llc}
\hline & High availability & Low availability \\
\hline $\begin{array}{l}\text { Buildings energy consumption per } \\
\mathrm{m}^{2} \text { (see } \mu_{\mathrm{h}} \text { in Equation 2) }\end{array}$ & 1 & $\begin{array}{c}\text { Trend starting at 1, reaching } 1.2 \text { in } \\
2030 \text { and staying at } 1.2 \text { after }\end{array}$ \\
\hline $\begin{array}{l}\text { Learning rate for very low energy } \\
\text { buildings }\end{array}$ & 0.08 & 0.03 \\
\hline
\end{tabular}

\section{A.3. Induced energy efficiency}

In each sector, the country with the lowest energy intensity is the leader and its energy efficiency is triggered by energy prices. After a delay, the other countries catch up with the leader. We build two hypotheses (see Table 7) using the following parameters: maximum annual improvement in the leader's energy efficiency, other countries' speed of convergence (\% of the initial gap after 50 years) and asymptotic level of catch up (\% of the leader's energy efficiency).

Table 7: Parameters options for energy efficiency

\begin{tabular}{lll}
\hline & Fast & Slow \\
\hline Maximum annual improvement in the leader's energy efficiency & 1.5 & 0.7 \\
\hline Other countries speed of convergence (\% of the initial gap after 50 years) & 10 & 50 \\
\hline Asymptotic level of catch-up (\% of the leader's energy efficiency) & 95 & 60 \\
\hline
\end{tabular}




\section{A.4. Fossil fuels - resources and markets}

\section{A.4.1. Oil}

The modeling structure of oil supply in Imaclim-R is based on a physical description of oil resources with an explicit differentiation according to the region and nature (conventional vs. non- conventional) to describe changes in oil producing capacities. Oil resource availability is based on data from USGS (2000), Greene et al. (2006) and Rogner (1997). The temporal availability for production of a given category of oil resources depends on the characteristics of the discovery process, which is subject to two main effects: the information effect (the more an oil slick is exploited, the more information about the localization of remaining resources is obtained) and the depletion effect (the more a slick is exploited, the less oil remains in the soil). Following Rehrl and Friedrich (2006), inertias in the deployment of oil producing capacities resulting from the combination of these effects are captured through bell-shaped curves that determine the changes in the oil producing capacities over time for each category of oil in each region.

We distinguish the different categories of regional oil resources according to their production costs (i.e. including exploration and exploitation costs) and the nature of the resource (conventional or nonconventional). To this end, we associate a bell-shaped time profile of its production with each resource category:

$$
\frac{Q_{\infty} \cdot b \cdot e^{-b\left(t-t_{0}\right)}}{\left(1+e^{-b\left(t-t_{0}\right)}\right)^{2}}
$$

where $t$ is the current date, $t_{0}$ is the starting date of oil production for this category, $Q_{\infty}$ is the amount of ultimate resources and $b$ is a parameter that captures the intensity of constraints that slow down production growth.

Concerning the dynamics of production capacities, Imaclim-R distinguishes two types of oil producers according to their investment behaviors. All non-Middle-Eastern countries are assumed to be motivated by short-term returns on investments, which implies that they will bring a category of oil reserve into production as soon as it becomes profitable (that is when the selling price on world market exceeds the total cost of exploration and exploitation). From then on, the deployment of production capacities is limited by geological constraints and strictly follows the corresponding bell shaped curve. The situation is different for Middle Eastern producers, as the amount of their oil resource gives them market power and allows them to choose a strategy to fulfill a specific objective (either a price or a market share target). For a given year, Middle Eastern production capacity is still bounded by a bell-shaped curve but its actual production may be below this limit if the chosen strategy requires a restriction on production.

Middle Eastern countries can use their market power in two opposite ways (and any combination in between). The first is to secure high prices in the short run by limiting the expansion of their production capacities; but this strategy has the disadvantage of encouraging oil importing countries to accelerate their efforts to develop oil free technologies and to adopt energy-sober consumption patterns. The second one is a "market flooding" strategy to maintain rather low prices in the short-term to encourage oil consumption and discourage oil importing countries from continuing efforts to save oil. Within this oil supply module, we decided to explore the uncertainty on the components of three major parameters to 
describe different levels of oil scarcity: the amount of ultimately recoverable resources, the level of inertia that will shape the development of non-conventional production, and the target oil price in Middle Eastern countries strategy (see Table 8).

\section{A.4.2. Gas}

In the model, gas world production capacities match demand growth until ultimately recoverable resources enter a depletion process. Variations in gas prices are indexed on variations in oil prices via an indexation coefficient (0.68, see Equation 5) calibrated on the World Energy Model (IEA, 2007). When oil prices increase by $1 \%$, gas prices increase by $0.68 \%$.

Two alternative assumptions are used in this price indexation. Under the assumption "relatively abundant and cheap" for the fossil fuel resources and market parameter set, this indexation disappears when oil prices reach $80 \$ / \mathrm{bl}$ : beyond this threshold, fluctuations in gas prices only depend on production costs and possibly on the depletion effect. When depletion is reached, price increases. Under the assumption "relatively scarce and expensive", gas prices remain indexed on oil prices regardless of fluctuations, but an additional price increase occurs when gas production enters its depletion phase.

The price of gas in each region at year $t$ is:

$$
p_{\text {gas }}(t)=p_{\text {gas }}^{r e f} \cdot \tau_{\text {gas }}(t)
$$

where $p_{g a s}^{\text {ref }}$ is the gas price in this region at year 1 .

As long as gas depletion has not started, $\tau_{\text {gas }}(t)$ in each region is:

$$
\tau_{\text {gas }}(t)=0.68 \cdot\left(\frac{1}{3} \cdot w p_{\text {oil }}(t)+\frac{2}{3} \cdot w p_{\text {oil }}(t-1)\right) \cdot \frac{1}{w p_{\text {oil }}^{\text {ref }}}
$$

Where $w p_{\text {oil }}(t)$ is the world oil price at year $t ; w p_{o i l}^{r e f}$ is the world oil price at year 1.

If depletion has started in this region, $\tau_{\text {gas }}(t)$ increases $5 \%$ each year, regardless of oil prices.

\section{A.4.3. Coal}

Coal is treated in a different way than oil and gas because more coal resources are available, which prevents coal production from entering a depletion process before the end of the 21st century.

We describe price formation on the world coal market in a reduced functional form linking variations in price to variations in production. This choice allows us to capture the cyclic behaviour of this commodity market. Coal prices then depend on current production through an elasticity coefficient $\eta_{\text {coal }}$ tight coal markets exhibit a high value of $\eta_{\text {coal }}$ (i.e. the price of coal increases if coal production increases). We make two assumptions for $\eta_{\text {coal }}$ (see Table 8 ). Under the assumption of "relatively abundant and cheap" the sensitivity of an increase in coal price to an increase in coal production is quite low, so that the increase in coal production can be absorbed without price fluctuations. Conversely, the increase in coal price is very sensitive to any increase in coal production under the assumption "relatively scarce and expensive". 
Table 8: Parameters options for fossil fuels

\begin{tabular}{|l|l|c|}
\hline & Relatively abundant & Relatively scarce \\
\hline Oil & & \\
\hline Amount of ultimately recoverable resources $\left(Q_{\infty}\right)$ & $3.6 \mathrm{~Tb}$ & $3.1 \mathrm{~Tb}$ \\
\hline $\begin{array}{l}\text { Inertia in the deployment of non-conventionals } \\
\text { (spread of the bell-shaped curve } b \text { ) }\end{array}$ & No inertia $(b=0.061)$ & $\begin{array}{l}\text { Inertia } \\
(b=0.041)\end{array}$ \\
\hline Middle Eastern countries target oil price & $80 \$ / \mathrm{bl}$ & $120 \$ / \mathrm{bl}$ \\
\hline Gas & & No threshold \\
\hline Indexation of gas price on oil price & $\mathrm{p}_{\text {oil } / \mathrm{gas}}=80 \$ / \mathrm{bl}$ & \\
\hline Coal & & 2 \\
\hline Price growth elasticity to production variations $\left(\eta_{\text {coal }}\right)$ & 1.5 & \\
\hline
\end{tabular}

\section{References}

Greene, D. L., Hopson, J. L., Li, J., Mar. 2006. Have we run out of oil yet? oil peaking analysis from an optimist's perspective. Energy Policy 34 (5), 515-531.

Grubler, A., Nakicenovic, N., Victor, D. G., May 1999. Dynamics of energy technologies and global change. Energy Policy 27 (5), 247-280.

IEA, 2007. World energy outlook. Tech. rep., IEA/OECD, Paris, France.

Laherrere, J., 2002. Forecasting future production with past discoveries. International Journal of Global Energy Issues 18 (2-4), 218-238.

LEPII-EPE, 2006. The POLES model, POLES State of the Art. Institut d'économie et de Politique de l'énergie, Grenoble, France.

Rehrl, T., Friedrich, R., 2006. Modelling long-term oil price and extraction with a hubbert approach: The LOPEX model. Energy Policy 34 (15), 2413-2428.

Rogner, $H_{.}, 1997$. An assessment of world hydrocarbon resources. Annual review of energy and the environment 22, 217-262.

Solow, R. M., 1956. A contribution to the theory of economic growth. Quarterly Journal of Economics $70,65-94$

USGS, 2000. World petroleum assessment 2000. Tech. rep., United States Geological Survey, USA, Washington. 


\section{Supplementary material}

\section{Regional and sectoral aggregation of Imaclim-R model}

\begin{tabular}{c|c}
\hline Regions & Sectors \\
\hline USA, & Coal, \\
Canada, & Oil, \\
Europe, & Gas, \\
Pacific OECD (Japan, Australia, & Liquid fuel refinery, \\
New-Zealand, South Korea), & Power generation, \\
Commonwealth of Independent & Air transportation, \\
States, & Maritime and \\
China, & transportation, \\
India, & Terrestrial transportation, \\
Brazil, & Construction, \\
Middle East, & Agriculture, \\
Africa, & Industry, \\
Rest of Asia, & Composite sector (services and \\
Rest of Latin America. & light industry). \\
\end{tabular}

Publications where specific modules of the model Imaclim- $R$ are explained

\begin{tabular}{|c|c|c|}
\hline & $\begin{array}{l}\text { Description of Imaclim-R } \\
\text { structure and results }\end{array}$ & $\begin{array}{l}\text { Models comparison (including } \\
\text { Imaclim-R) }\end{array}$ \\
\hline Technologies & $\begin{array}{l}\text { Bibas and Méjean (2014) } \\
\text { (bioenergy) }\end{array}$ & $\begin{array}{l}\text { Kim et al. (2014) (nuclear) } \\
\text { Koelbl et al. (2014) (CCS) } \\
\text { Krey et al. (2014) } \\
\text { Kriegler et al. (2014) } \\
\text { Luderer et al. (2014) } \\
\text { (renewables) } \\
\text { Rose et al. (2014) (bioenergy) } \\
\text { Tavoni et al. (2012) }\end{array}$ \\
\hline Energy efficiency & Bibas et al. (2015) & Sugiyama et al. (2014) \\
\hline Fossil fuels & $\begin{array}{l}\text { Rozenberg et al. (2010) } \\
\text { Waisman et al. (2012) } \\
\text { Waisman et al. (2013a) }\end{array}$ & $\begin{array}{l}\text { Bauer et al. (2015) } \\
\text { MCCollum et al. (2014) }\end{array}$ \\
\hline Transport & Waisman et al. (2013b) & \\
\hline Macroeconomy & $\begin{array}{c}\text { Crassous et al. (2006) } \\
\text { (endogenous structural change) } \\
\text { Guivarch et al. (2011) (labor }\end{array}$ & \\
\hline
\end{tabular}




\begin{tabular}{|c|c|c|}
\hline & markets) & \\
\hline $\begin{array}{l}\text { Evaluation of } \\
\text { model }\end{array}$ & $\begin{array}{l}\text { Guivarch et al. (2009) (b } \\
\text { ackcasting) }\end{array}$ & $\begin{array}{c}\text { Kriegler et al. (2015b) } \\
\text { (diagnostics) }\end{array}$ \\
\hline \multirow[t]{5}{*}{ Scenarios } & Guivarch and Mathy (2012) & Blanford et al. (2014) \\
\hline & Hamdi-Cherif et al. (2011) & Kriegler et al. (2015) \\
\hline & Mathy and Guivarch (2010) & Luderer et al. (2012a) \\
\hline & Rozenberg et al. (2014) & Luderer et al. (2012b) \\
\hline & Waisman et al. (2014) & Riahi et al. (2015) \\
\hline
\end{tabular}

Bauer, Nico, Valentina Bosetti, Meriem Hamdi-Cherif, Alban Kitous, David McCollum, Aurélie Méjean, Shilpa Rao, Hal Turton, Leonidas Paroussos, et Shuichi Ashina. 2015. CO2 emission mitigation and fossil fuel markets: Dynamic and international aspects of climate policies. Technological Forecasting and Social Change 90 (Part A), 243-256.

Bibas R., and A. Méjean (2014). Potential and limitations of bioenergy for low carbon transitions. Climatic Change, 123(3-4) 731-761

Bibas, R., Méjean, A., Hamdi-Cherif, M., 2015. Energy efficiency policies and the timing of action: An assessment of climate mitigation costs. Technological Forecasting and Social Change 90 (part A), 137-152. Blanford, Geoffrey J., Elmar Kriegler, et Massimo Tavoni. 2014. « Harmonization vs. fragmentation: overview of climate policy scenarios in EMF27 ». Climatic Change 123 (3-4), 38396.

Crassous, R., J. C Hourcade, et O. Sassi. 2006. «Endogenous structural change and climate targets modeling experiments with Imaclim-R ». Energy Journal 27: 25976.

Guivarch, Céline, Stéphane Hallegatte, et Renaud Crassous. 2009. "The resilience of the Indian economy to rising oil prices as a validation test for a global energy-environment-economy CGE model ». Energy Policy 37 (11): 425966.

Guivarch, C., Crassous, R., Sassi, O., Hallegatte, S. 2011. 'The costs of climate policies in a second best world with labour market imperfections'. Climate Policy 11 : 768-788.

Guivarch, C., Mathy, S. 2012. 'Energy-GDP decoupling in a second best world-a case study on India' Climatic Change, Volume 113, Number 2, 339-356.

Hamdi-Cherif, M., Guivarch, C., Quirion, P. 2011. 'Sectoral targets for developing countries: Combining "Common but differentiated responsibilities" with "Meaningful participation"',Climate Policy 11: 731-751. Kim, Son H., Kenichi Wada, Atsushi Kurosawa, et Matthew Roberts. 2014. " Nuclear energy response in the EMF27 study ». Climatic Change 123 (3-4): 44360.

Koelbl, Barbara Sophia, Machteld A. van den Broek, André PC Faaij, et Detlef P. van Vuuren. 2014. « Uncertainty in Carbon Capture and Storage (CCS) deployment projections: a cross-model comparison exercise ». Climatic Change 123 (3-4): 46176.

Krey, Volker, Gunnar Luderer, Leon Clarke, et Elmar Kriegler. 2014. " Getting from here to there-energy technology transformation pathways in the EMF27 scenarios ». Climatic Change 123 (3-4), 36982. Kriegler, Elmar, John P. Weyant, Geoffrey J. Blanford, Volker Krey, Leon Clarke, Jae Edmonds, Allen Fawcett, et al. 2014. «The Role of Technology for Achieving Climate Policy Objectives: Overview of the EMF 27 Study on Global Technology and Climate Policy Strategies ». Climatic Change 123 (3-4), 35367. 
Kriegler E., K. Riahi, N. Bauer, V.J. Schanitz, N. Petermann, V. Bosetti, A. Marcucci, S. Otto, L. Paroussos, and et al. (2015a). Making or breaking climate targets: The AMPERE study on staged accession scenarios for climate policy. Technological Forecasting and Social Change 90 (Part A), 24-44.

Kriegler, Elmar, Nils Petermann, Volker Krey, Valeria Jana Schwanitz, Gunnar Luderer, Shuichi Ashina, Valentina Bosetti, Jiyong Eom, Alban Kitous, et Aurélie Méjean. 2015b. Diagnostic indicators for integrated assessment models of climate policy. Technological Forecasting and Social Change. 90 (Part A), 45-61. Luderer G, DeCian E, Hourcade JC, Leimbach M, Waisman H et Edenhofer O (2012a). " On the regional distribution of mitigation costs in a global cap-and-trade regime", Climatic Change 114 (1), 59-78.

Luderer G, Bosetti V, Jakob M, Steckel J, Waisman H et Edenhofer O (2012b). "The Economics of GHG Emissions Reductions - results and insights from the RECIPE model intercomparison", Climatic Change 114 (1), 9-37.

Luderer, Gunnar, Volker Krey, Katherine Calvin, James Merrick, Silvana Mima, Robert Pietzcker, Jasper Van Vliet, et Kenichi Wada. 2014. "The role of renewable energy in climate stabilization: results from the EMF27 scenarios ». Climatic Change 123 (3-4): 42741.

Mathy, S., Guivarch, C. 2010. 'Climate policies in a second-best world - A case study on India', Energy Policy 38:3, 1519-1528.

McCollum, David, Nico Bauer, Katherine Calvin, Alban Kitous, et Keywan Riahi. 2014. « Fossil resource and energy security dynamics in conventional and carbon-constrained worlds ». Climatic Change 123 (3-4): 41326.

Riahi K., E. Kriegler, N. Johnson, C. Bertram, M. Den Elzen, J. Eom, M. Schaeffer, J. Edmonds, and et al. (2015). Locked into Copenhagen Pledges - Implications of short-term emission targets for the cost and feasibility of long-term climate goals. Technological Forecasting and Social Change 90 (Part A), 8-23. Rose, Steven K., Elmar Kriegler, Ruben Bibas, Katherine Calvin, Alexander Popp, Detlef P. van Vuuren, et John Weyant. 2014. «Bioenergy in energy transformation and climate management ». Climatic Change 123 (3-4): 47793.

Rozenberg, Julie, Stéphane Hallegatte, Adrien Vogt-Schilb, Olivier Sassi, Céline Guivarch, Henri Waisman, et Jean-Charles Hourcade. 2010. "Climate policies as a hedge against the uncertainty on future oil supply ». Climatic Change 101 (3): 66368.

Rozenberg, J., Guivarch, C., Lempert, R., Hallegatte, S. 2014. Building SSPs for climate policy analysis: a scenario elicitation methodology to map the space of possible future challenges to mitigation and adaptation. Climatic Change 122(3), pp 509-522.

Sugiyama, Masahiro, Osamu Akashi, Kenichi Wada, Amit Kanudia, Jun Li, et John Weyant. 2014. «Energy Efficiency Potentials for Global Climate Change Mitigation ». Climatic Change 123 (3-4): 397411.

Tavoni M, DeCian E, Luderer G, Steckel JC et Waisman H (2012). "The value of technology and of its evolution towards a low carbon economy", Climatic Change 114 (1), 39-57.

Waisman, Henri, Julie Rozenberg, Olivier Sassi, et Jean-Charles Hourcade. 2012. "Peak Oil profiles through the lens of a general equilibrium assessment ». Energy Policy, Special Section: Frontiers of Sustainability, 48: 74453. 
Waisman, Henri, Julie Rozenberg, et Jean Charles Hourcade. 2013. «Monetary compensations in climate policy through the lens of a general equilibrium assessment: The case of oil-exporting countries ». Energy Policy 63: 95161.

Waisman, H.D., Guivarch, C., Lecocq, C. 2013. 'The transportation sector and low-carbon growth pathways' Climate Policy 13(1): 106-129.

Waisman Henri-David, Cassen Chritophe, Hamdi-Cherif Meriem and Hourcade Jean-Charles, 2014.

Sustainability, Globalization, and the Energy Sector - Europe in a Global Perspective. Journal of Environment and Development, Volume 23 (1), 101-132. 